\title{
INFLUENCE OF MODEL PARAMETERS ON VEHICLE SUSPENSION CONTROL
}

\author{
Sérgio Junichi Idehara ${ }^{1}$, Matheus Rogério Roesler Sabka ${ }^{2}$ \\ ${ }^{1}$ Campus of Joinville, Federal University of Santa Catarina, Santa Catarina, Brazil \\ ${ }^{2}$ Campus of Joinville, Federal University of Santa Catarina, Santa Catarina, Brazil
}

\begin{abstract}
Numerical models are widely used to characterize the vehicle dynamics in order to control the active suspension process. However, little information is available on the evaluation of performance when the model parameters do not match real vehicle configurations. Obtaining estimates of the influence of these factors on the system control requires statistical analysis, which generates stochastic data on the issue under consideration. A sensitivity analysis of the test data is one the most successful approaches to this type of problem. A Monte Carlo simulation with uncertainty parameters for mass, front and rear stiffness and damping was used with design of experiments analysis to evaluate the performance of three methods of active suspension control (PID, MPC and LQR). In this study a sensitivity analysis was developed to determine the relevant factors and the crosscorrelation effects of their features. The methodology is applied to a model of a passenger car, which is excited by an asymmetric speed bump and uneven road profile. The changes in the behavior of the main parameters of each controller were observed and evaluated as improved for the PID and MPC controllers and worsened for the LQR controller when compared to the designed condition.
\end{abstract}

Keywords: Vehicle dynamic, suspension, active control, and sensitivity analysis

\section{INTRODUCTION}

Suspension control has been the focus of many studies to improve the dynamic behavior of vehicles aimed at increasing automotive safety and comfort. The application of active or semi-active suspension control has expanded and it is used to improve ride comfort, by isolating the chassis from road excitations, and to guarantee the road holding characteristics. With the aim of reducing the motion of the sprung mass, active control is used to store, dissipate or even generate energy, whereas semi-active control only dissipates energy [1]. As examples, some researchers [2, 3] have used suspension control to reduce the vibration of the vehicle passengers. The model considers the dynamics of the person with reference to the head acceleration. The method employed was linear $\mathrm{H} \infty$ control, which was more effective than a single controlled vehicle model. Also, the application of adaptive strategies has been used to improve the control methods. Specifically, [4] compares different controllers, such as proportional-integral-derivative (PID) and linear quadratic regulator (LQR), with a proposed method using feedback error learning (FEL) on a quarter vehicle model. This method employs a fuzzy neural network with LQR control to optimize the suspension system. The results indicate better conditions for ride comfort, steering and stability of the vehicle dynamics. In models applied in previous research, preview active suspension control was used to improve performance based on measurements of road irregularities [5, 6]. For instance, [7] evaluates two types of prediction in the controller: a look-ahead preview with information on the irregularities of the track ahead of the vehicle; and a wheelbase preview, to improve the performance of the rear suspension based on information obtained from the front wheels. Suspension control was simulated based on the optimal control theory for a half-car model. The results indicate that better performance of the active suspension can be obtained with a combination of the two methods, wheelbase and look-ahead previews. Thus, suspension control is important to vehicle engineering and some of the techniques available in this regard are listed in Table 1, [8-14].

Table 1: Suspension control methods described in the literature

\begin{tabular}{|c|l|l|l|c|}
\hline Literature & \multicolumn{1}{|c|}{$\begin{array}{c}\text { Control } \\
\text { concept }\end{array}$} & Model & Control & Year \\
\hline$[8]$ & LQ theory & $\begin{array}{l}\text { Full } \\
\text { vehicle }\end{array}$ & $\begin{array}{l}\text { Semi- } \\
\text { active }\end{array}$ & 2013 \\
\hline$[9]$ & LPV theory & $\begin{array}{l}\text { Quarter } \\
\text { car }\end{array}$ & $\begin{array}{l}\text { Semi- } \\
\text { active }\end{array}$ & 2008 \\
\hline$[10]$ & MPC & Half car & $\begin{array}{l}\text { Semi- } \\
\text { active }\end{array}$ & 2006 \\
\hline$[11]$ & $\begin{array}{l}\text { Mixed H2 } \\
\text { and } \mathrm{H}_{\infty}\end{array}$ & $\begin{array}{l}\text { Full } \\
\text { vehicle }\end{array}$ & $\begin{array}{l}\text { Semi- } \\
\text { active }\end{array}$ & 2010 \\
\hline$[12]$ & $\begin{array}{l}\text { Fault- } \\
\text { tolerant } \\
\text { robust } \mathrm{H}_{\infty}\end{array}$ & $\begin{array}{l}\text { Full } \\
\text { vehicle }\end{array}$ & Active & 2015 \\
\hline$[13]$ & $\begin{array}{l}\text { PID } \\
\text { Quarter } \\
\text { car }\end{array}$ & Active & 2012 \\
\hline$[14]$ & $\begin{array}{l}\text { Modal non- } \\
\text { linear } \\
\text { skyhook }\end{array}$ & $\begin{array}{l}\text { Model } \\
\text { free }\end{array}$ & $\begin{array}{l}\text { Semi- } \\
\text { active }\end{array}$ & 2007 \\
\hline
\end{tabular}


The simulations in the cited studies use a quarter-car (single corner), half-car or full-car model as a base model, with 2, 4 and 7 degrees of freedom (dof), respectively. As another example of this type of modelling, on analyzing a complete heavy commercial vehicle, in [15] a semi-active suspension control was simulated using a multibody model with the cabin and trailer models from modal skyhook control. Therefore, there are several approaches to controlling the vehicle suspension; however, most of them require an accurate plant model. Thus, one of the challenges in suspension control is tuning the model parameters. In many studies today, the main challenge is dealing with the model uncertainties, seeking online compensation for unknown nonlinearities through adaptive control [16, 17]. Nevertheless, in the commercial vehicle context, traditional methods based on a vehicle model are still frequently applied. Thus, when developing a control technique, an understanding of the model parameters and their sensitivity is required to obtain a robust controller setup.

In this context, this article reports a study on the influence of the model parameters on the suspension control performance, where numerical experiments were conducted to obtain a statistical understanding of the system behavior. A Monte Carlo simulation and design of experiments (DoE) method were employed in this analysis. The vehicle model has seven degrees of freedom and is controlled by three types of controllers: proportional-integral-derivative (PID), model prediction control (MPC) and linear quadratic regulator (LQR) methods.

\section{MATHEMATICAL FORMULATION}

In the area of numerical simulation, models with seven dof have proven valuable for predicting the dynamics of vehicles. For example, Fig. 1 illustrates a vehicle with a sprung mass $\left(\mathrm{m}_{\mathrm{s}}\right)$ and four unsprung masses $\left(\mathrm{m}_{1}, \mathrm{~m}_{2}, \mathrm{~m}_{3}\right.$ and $\mathrm{m}_{4}$ ) from the wheels. The scheme also represents the suspension system with stiffness $\left(\mathrm{k}_{\mathrm{i}}\right)$ and damping $\left(\mathrm{c}_{\mathrm{i}}\right)$ for corners $i=1,2,3,4$. Tire stiffness and damping of the wheels are described by $\mathrm{k}_{\mathrm{t}}$ and $\mathrm{c}_{\mathrm{t}}$, respectively.

$$
\begin{aligned}
{[C] } & =\left[\begin{array}{ccccccc}
\mathrm{c}_{11} & \mathrm{c}_{12} & \mathrm{c}_{13} & -\mathrm{c}_{1} & -\mathrm{c}_{2} & -\mathrm{c}_{3} & -\mathrm{c}_{4} \\
\mathrm{c}_{21} & \mathrm{c}_{22} & \mathrm{c}_{23} & \mathrm{c}_{1} \cdot \mathrm{d}_{3} & \mathrm{c}_{2} \cdot \mathrm{d}_{3} & -\mathrm{c}_{3} \cdot \mathrm{d}_{4} & -\mathrm{c}_{4} \cdot \mathrm{d}_{4} \\
\mathrm{c}_{31} & \mathrm{c}_{32} & \mathrm{c}_{33} & -\mathrm{c}_{1} \cdot \mathrm{d}_{1} & \mathrm{c}_{2} \cdot \mathrm{d}_{2} & -\mathrm{c}_{3} \cdot \mathrm{d}_{1} & \mathrm{c}_{4} \cdot \mathrm{d}_{2} \\
-\mathrm{c}_{1} & \mathrm{c}_{1} \cdot \mathrm{d}_{3} & -\mathrm{c}_{1} \cdot \mathrm{d}_{1} & \mathrm{c}_{\mathrm{t}}+\mathrm{c}_{1} & 0 & 0 & 0 \\
-\mathrm{c}_{2} & \mathrm{c}_{2} \cdot \mathrm{d}_{3} & \mathrm{c}_{2} \cdot \mathrm{d}_{2} & 0 & \mathrm{c}_{\mathrm{t}}+\mathrm{c}_{2} & 0 & 0 \\
-\mathrm{c}_{3} & -\mathrm{c}_{3} \cdot \mathrm{d}_{4} & -\mathrm{c}_{3} \cdot \mathrm{d}_{1} & 0 & 0 & \mathrm{c}_{\mathrm{t}}+\mathrm{c}_{3} & 0 \\
-\mathrm{c}_{4} & -\mathrm{c}_{4} \cdot \mathrm{d}_{4} & \mathrm{c}_{4} \cdot \mathrm{d}_{2} & 0 & 0 & 0 & \mathrm{c}_{\mathrm{t}}+\mathrm{c}_{4}
\end{array}\right] \text { is the damping matrix, } \\
{[\mathrm{K}] } & =\left[\begin{array}{ccccccc}
\mathrm{k}_{11} & \mathrm{k}_{12} & \mathrm{k}_{13} & -\mathrm{k}_{1} & -\mathrm{k}_{2} & -\mathrm{k}_{3} & -\mathrm{k}_{4} \\
\mathrm{k}_{21} & \mathrm{k}_{22} & \mathrm{k}_{23} & \mathrm{k}_{1} \cdot \mathrm{d}_{3} & \mathrm{k}_{2} \cdot \mathrm{d}_{3} & -\mathrm{k}_{3} \cdot \mathrm{d}_{4} & -\mathrm{k}_{4} \cdot \mathrm{d}_{4} \\
\mathrm{k}_{31} & \mathrm{k}_{32} & \mathrm{k}_{33} & -\mathrm{k}_{1} \cdot \mathrm{d}_{1} & \mathrm{k}_{2} \cdot \mathrm{d}_{2} & -\mathrm{k}_{3} \cdot \mathrm{d}_{1} & \mathrm{k}_{4} \cdot \mathrm{d}_{2} \\
-\mathrm{k}_{1} & \mathrm{k}_{1} \cdot \mathrm{d}_{3} & -\mathrm{k}_{1} \cdot \mathrm{d}_{1} & \mathrm{k}_{\mathrm{t}}+\mathrm{k}_{1} & 0 & 0 & 0 \\
-\mathrm{k}_{2} & \mathrm{k}_{2} \cdot \mathrm{d}_{3} & \mathrm{k}_{2} \cdot \mathrm{d}_{2} & 0 & \mathrm{k}_{\mathrm{t}}+\mathrm{k}_{2} & 0 & 0 \\
-\mathrm{k}_{3} & -\mathrm{k}_{3} \cdot \mathrm{d}_{4} & -\mathrm{k}_{3} \cdot \mathrm{d}_{1} & 0 & 0 & \mathrm{k}_{\mathrm{t}}+\mathrm{k}_{3} & 0 \\
-\mathrm{k}_{4} & -\mathrm{k}_{4} \cdot \mathrm{d}_{4} & \mathrm{k}_{4} \cdot \mathrm{d}_{2} & 0 & 0 & 0 & \mathrm{k}_{\mathrm{t}}+\mathrm{k}_{4}
\end{array}\right] \text { is the stiffness matrix, }
\end{aligned}
$$

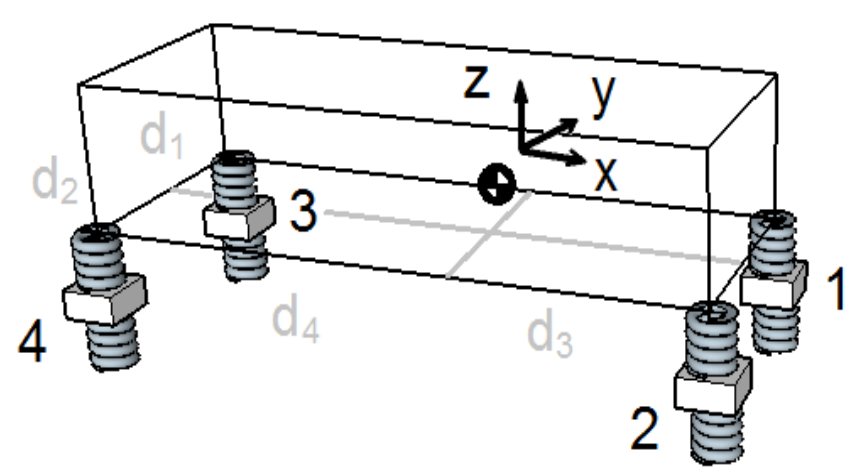

Fig 1: Illustration of vehicle model with seven dof and its dimensions

\subsection{Vehicle Dynamics}

The equation of motion, derived from this seven dof model, represents the vehicle motions of pitch, bounce and roll and the vertical movement of the wheels. The differential equation solution generates the time response for the vertical movement of the sprung mass (z), angular displacement around the $\mathrm{x}$-axis $\left(\theta_{\mathrm{x}}\right)$ and the $\mathrm{y}$-axis $\left(\theta_{\mathrm{y}}\right)$ and the vertical movement of the unsprung mass $\left(\mathrm{x}_{1}, \mathrm{x}_{2}, \mathrm{x}_{3}\right.$ and $\left.\mathrm{x}_{4}\right)$. According to this model, the control force of the active suspension is attributed to input excitation $\{\mathrm{u}(\mathrm{t})\}$ and the other force, $\{\mathrm{f}(\mathrm{t})\}$, is the road excitation force. Thus, the equation of motion is written as:

$[M] .\{\ddot{x}\}+[C] .\{\dot{x}\}+[K] .\{x\}=\{f(t)\}+\{u(t)\}$,

where,

$\{\mathrm{x}\}=\left\{\begin{array}{lllllll}\mathrm{z} & \theta_{\mathrm{y}} & \theta_{\mathrm{x}} & \mathrm{x}_{1} & \mathrm{x}_{2} & \mathrm{x}_{3} & \mathrm{x}_{4}\end{array}\right\}$, and $\{\dot{\mathrm{x}}\}$ and $\{\ddot{\mathrm{x}}\}$ are the first and second time derivates of $\{x\}$,

$[\mathrm{M}]=\operatorname{diag}\left\{\begin{array}{lllllll}\mathrm{m}_{\mathrm{s}} & \mathrm{J}_{\mathrm{y}} & \mathrm{J}_{\mathrm{x}} & \mathrm{m}_{1} & \mathrm{~m}_{2} & \mathrm{~m}_{3} & \mathrm{~m}_{4}\end{array}\right\} \quad$ is the mass matrix, 
$\{\mathrm{f}(\mathrm{t})\}=$

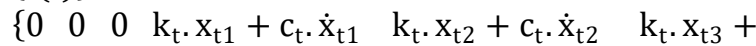

ct.xt3 kt.xt4+ct.xt4T is the vector of excitation forces on the wheels and $\{\mathrm{u}(\mathrm{t})\}$ is the control force of the suspension, with $\mathrm{x}_{\mathrm{ti}}$ being the base excitation from road irregularities for suspensions $1,2,3$ and 4 .

The matrix elements are:

$c_{11}=\sum_{1}^{4} c_{i}$,

$c_{12}=c_{21}=-c_{1} \cdot d_{3}-c_{2} \cdot d_{3}+c_{3} \cdot d_{4}+c_{4} \cdot d_{4}$,

$c_{13}=c_{31}=c_{1} \cdot d_{1}-c_{2} \cdot d_{2}+c_{3} \cdot d_{1}-c_{4} \cdot d_{2}$,

$c_{22}=c_{1} \cdot d_{3}^{2}+c_{2} \cdot d_{3}^{2}+c_{3} \cdot d_{4}^{2}+c_{4} \cdot d_{4}^{2}$,

$c_{23}=c_{32}=-c_{1} \cdot d_{1} \cdot d_{3}+c_{2} \cdot d_{2} \cdot d_{3}+c_{3} \cdot d_{1} \cdot d_{4}-$

$c_{4} \cdot d_{2} \cdot d_{4}$

$c_{33}=c_{1} \cdot d_{1}^{2}+c_{2} \cdot d_{2}^{2}+c_{3} \cdot d_{1}^{2}+c_{4} \cdot d_{2}^{2}$.

$k_{11}=\sum_{1}^{4} k_{i}$

$k_{12}=k_{21}=-k_{1} \cdot d_{3}-k_{2} \cdot d_{3}+k_{3} \cdot d_{4}+k_{4} \cdot d_{4}$,

$k_{13}=k_{31}=k_{1} \cdot d_{1}-k_{2} \cdot d_{2}+k_{3} \cdot d_{1}-k_{4} \cdot d_{2}$,

$k_{22}=k_{1} \cdot d_{3}^{2}+k_{2} \cdot d_{3}^{2}+k_{3} \cdot d_{4}^{2}+k_{4} \cdot d_{4}^{2}$,

$k_{23}=k_{32}=-k_{1} \cdot d_{1} \cdot d_{3}+k_{2} \cdot d_{2} \cdot d_{3}+k_{3} \cdot d_{1} \cdot d_{4}-$

$k_{4} \cdot d_{2} \cdot d_{4}$,

$k_{33}=k_{1} \cdot d_{1}^{2}+k_{2} \cdot d_{2}^{2}+k_{3} \cdot d_{1}^{2}+k_{4} \cdot d_{2}^{2}$.

The magnitude of the torque on the $\mathrm{x}$-axis $\left(\mathrm{M}_{\mathrm{x}}\right)$ and $\mathrm{y}$-axis $\left(\mathrm{M}_{\mathrm{y}}\right)$ of the sprung mass is found by a geometric transformation matrix $(\mathrm{T})$ from suspension forces:

$\left\{\begin{array}{l}M_{x} \\ M_{y}\end{array}\right\}=\left[\begin{array}{cccc}d_{1} & -d_{2} & d_{1} & -d_{2} \\ -d_{3} & -d_{3} & d_{4} & d_{4}\end{array}\right]\left\{\begin{array}{l}f_{1} \\ f_{2} \\ f_{3} \\ f_{4}\end{array}\right\}=[T] .\left\{\begin{array}{l}f_{1} \\ f_{2} \\ f_{3} \\ f_{4}\end{array}\right\}$

where, $\mathrm{f}_{1}, \mathrm{f}_{2}, \mathrm{f}_{3}, \mathrm{f}_{4}$ are the suspension forces at the vehicle corners (sprung mass).

The values used in the numerical simulations of a full vehicle excited by a transient excitation from vehicle tire contact to evaluate the influence of the active suspension on the vibration are shown in the Table 2.

Table 2: Seven-dof car parameters

\begin{tabular}{|l|c|c|}
\hline Variable & Symbol & Value \\
\hline Sprung mass & $m_{s}$ & $678.00 \mathrm{~kg}$ \\
\hline $\begin{array}{l}\text { Front vehicle unsprung } \\
\text { mass }\end{array}$ & $m_{1}, m_{2}$ & $31.50 \mathrm{~kg}$ \\
\hline $\begin{array}{l}\text { Rear vehicle unsprung } \\
\text { mass }\end{array}$ & $m_{3}, m_{4}$ & $44.50 \mathrm{~kg}$ \\
\hline $\begin{array}{l}\text { Mass moment of } \\
\text { inertia x-axis }\end{array}$ & $J_{x}$ & $850 \mathrm{~kg} \cdot \mathrm{m}^{2}$ \\
\hline $\begin{array}{l}\text { Mass moment of } \\
\text { inertia y-axis }\end{array}$ & $J_{y}$ & $2.40 \times 10^{3} \mathrm{~kg} \cdot \mathrm{m}^{2}$ \\
\hline $\begin{array}{l}\text { Front suspension } \\
\text { stiffness }\end{array}$ & $k_{1}, k_{2}$ & $1.69 \times 10^{4} \mathrm{~N} / \mathrm{m}$ \\
\hline $\begin{array}{l}\text { Front suspension } \\
\text { damping coefficient }\end{array}$ & $c_{1}, c_{2}$ & $1.55 \times 10^{3} \mathrm{~N} . \mathrm{s} / \mathrm{m}$ \\
\hline
\end{tabular}

\begin{tabular}{|l|c|c|}
\hline $\begin{array}{l}\text { Rear suspension } \\
\text { stiffness }\end{array}$ & $k_{3}, k_{4}$ & $1.90 \times 10^{4} \mathrm{~N} / \mathrm{m}$ \\
\hline $\begin{array}{l}\text { Rear suspension } \\
\text { damping coefficient }\end{array}$ & $c_{3}, c_{4}$ & $3.14 \times 10^{3} \mathrm{~N} . \mathrm{s} / \mathrm{m}$ \\
\hline Tire stiffness & $k_{t}$ & $1.90 \times 10^{5} \mathrm{~N} / \mathrm{m}$ \\
\hline $\begin{array}{l}\text { Tire damping } \\
\text { coefficient }\end{array}$ & $c_{t}$ & 0.00 \\
\hline
\end{tabular}

\subsection{Vehicle Decoupled Controller}

A decoupled controller is based on a quarter car model, which considers two vibration dof and it sets out a sprung mass $\left(\mathrm{m}_{\mathrm{s}}\right)$ and unsprung mass $\left(\mathrm{m}_{\mathrm{us}}\right)$ motion (Fig. 2). The idea is to control independently each suspension with this model and select the optimal simulated parameters to find ways to reduce the vibration in the whole vehicle. To simulate the results for the control of the 7-dof vehicle, four 2-dof controls are used simultaneously (one for each suspension). This strategy is a good way to reduce the processing time and model complexity of the controller.

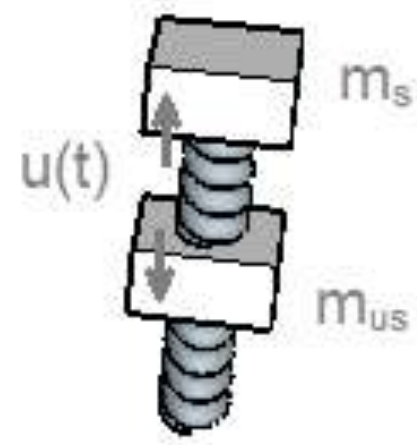

Fig 2: Quarter car model.

Similarly to the 7-dof model, the motion equation of the 2dof model is written as

$$
\begin{aligned}
& {\left[\begin{array}{cc}
m_{s} & 0 \\
0 & m_{u s}
\end{array}\right] \cdot\left\{\begin{array}{c}
\ddot{x}_{s} \\
\ddot{x}_{u s}
\end{array}\right\}+\left[\begin{array}{cc}
c & -c \\
-c & c+c_{t}
\end{array}\right] \cdot\left\{\begin{array}{c}
\dot{x}_{s} \\
\dot{x}_{u s}
\end{array}\right\}+} \\
& {\left[\begin{array}{cc}
k & -k \\
-k & k+k_{t}
\end{array}\right] \cdot\left\{\begin{array}{c}
x_{s} \\
x_{u s}
\end{array}\right\}=\left\{\begin{array}{c}
u(t) \\
-u(t)+f(t)
\end{array}\right\},}
\end{aligned}
$$

where $\mathrm{c}$ and $\mathrm{c}_{\mathrm{t}}$ are the suspension and tire damping coefficients, respectively, $\mathrm{k}$ and $\mathrm{k}_{\mathrm{t}}$ are the suspension and tire stiffness, respectively, $u(t)$ is the controller force, and $f(t)$ is the external excitation force on the tire. The numbers of dof are $\mathrm{x}_{\mathrm{s}}$ and $\mathrm{x}_{\mathrm{us}}$ for the displacement of the sprung mass and unsprung mass, respectively. The quarter car parameters are shown in Table 3.

Table 3: quarter car parameters

\begin{tabular}{|l|c|c|c|}
\hline Variable & Symbol & Front vehicle & Rear vehicle \\
\hline Sprung mass & $m_{s}$ & $169.50 \mathrm{~kg}$ & $169.50 \mathrm{~kg}$ \\
\hline $\begin{array}{l}\text { Unsprung } \\
\text { mass }\end{array}$ & $m_{u s}$ & $31.50 \mathrm{~kg}$ & $44.50 \mathrm{~kg}$ \\
\hline $\begin{array}{l}\text { Suspension } \\
\text { damping } \\
\text { coefficient }\end{array}$ & $c$ & $1.55 \times 10^{3} \mathrm{Ns} / \mathrm{m}$ & $3.14 \times 10^{3} \mathrm{Ns} / \mathrm{m}$ \\
\hline
\end{tabular}




\begin{tabular}{|l|c|c|c|}
\hline $\begin{array}{l}\text { Tire damping } \\
\text { coefficient }\end{array}$ & $c_{t}$ & 0.00 & 0.00 \\
\hline $\begin{array}{l}\text { Suspension } \\
\text { stiffness }\end{array}$ & $k$ & $1.69 \times 10^{4} \mathrm{~N} / \mathrm{m}$ & $1.90 \times 10^{4}$ \\
\hline Tire stiffness & $k_{t}$ & $1.90 \times 10^{5} \mathrm{~N} / \mathrm{m}$ & $1.90 \times 10^{5} \mathrm{~N} / \mathrm{m}$ \\
\hline
\end{tabular}

$$
\begin{aligned}
& {\left[\begin{array}{c}
0_{2 \times 1} \\
M_{2 \times 2}^{-1} \cdot L_{2 \times 1}
\end{array}\right] \cdot\left\{u_{1 \times 1}\right\},} \\
& \{d\}=\left[C_{s s}\right] \cdot\{\phi\}+\left[D_{s s}\right] .\{u\},
\end{aligned}
$$

where, $\mathrm{O}_{2 \times 2}=\left[\begin{array}{ll}0 & 0 \\ 0 & 0\end{array}\right]$ and $\mathrm{O}_{2 \times 1}=\left[\begin{array}{l}0 \\ 0\end{array}\right]$ are the zero matrix and vector, respectively, $\mathrm{L}=\left[\begin{array}{ll}1 & 0\end{array}\right]^{\mathrm{T}}$ is the actuator placement, $\left[\mathrm{C}_{\mathrm{ss}}\right]$ is the output matrix and $\left[\mathrm{D}_{\mathrm{ss}}\right]$ is the direct transition matrix. By representing as a function of state and input matrix, respectively:

$\begin{aligned} A_{4 \times 4} & =\left[\begin{array}{cc}O_{2 \times 2} & I_{2 \times 2} \\ -M_{2 \times 2}^{-1} \cdot K_{2 \times 2} & -M_{2 \times 2}^{-1} \cdot C_{2 \times 2}\end{array}\right] \\ B_{4 \times 1} & =\left[\begin{array}{c}0_{2 \times 1} \\ M_{2 \times 2}^{-1} \cdot L_{2 \times 1}\end{array}\right],\end{aligned}$ and input to the controller. In this paper, the three algorithms used are (a) a PID control, (b) an explicit model predictive control (MPC) and (c) a linear quadratic regulator (LQR), which are written in the Matlab program based on a desired signal $\left(\mathrm{d}^{*}(\mathrm{t})\right)$, according to the formulations and conditions described in the following sections. In this case, the desired signal, sprung mass vibration, is $\mathrm{d}^{*}(\mathrm{t})=0$.

\subsection{PID control}

The proportional-integral-derivative (PID) control is described by a force determined as

$$
u(t)=K \cdot\left(e(t)+T_{d} \cdot \frac{d e(t)}{d t}+\frac{1}{T_{i}} \cdot \int_{0}^{t} e(\tau) \cdot d \tau\right) .
$$

where, $e(t)$ is the control error between the system response (d) and the reference signal or set point $\left(\mathrm{d}^{*}\right)$. In relation to the controller constants, $\mathrm{K}$ is a proportional gain, $\mathrm{T}_{\mathrm{d}}$ a time derivative and $T_{i}$ a time integral. In the discrete form we have the following:

$$
\begin{aligned}
& u[k]= \\
& K_{p} \cdot e[k]+K_{d} \cdot \frac{e[k]-e[k-1]}{\Delta t}+ \\
& +K_{i} \cdot \sum_{n=1}^{k} e[n] . \Delta t, \\
& e[k]=d^{*}[k]-d[k] \text {. }
\end{aligned}
$$

where, $K_{p}=K, K_{d}=K \cdot T_{d}$ and $K_{i}=\frac{K}{T_{i}}$ are the gains of the proportional, derivative and integral terms. In the simulations, the numerical values for the constants are $\mathrm{K}_{\mathrm{p}}=10000, \mathrm{~K}_{\mathrm{d}}=8000$ and $\mathrm{K}_{\mathrm{i}}=4000$.

\subsection{Explicit Model Predictive Control}

The model predictive control (MPC) is a control method commonly employed by researchers and engineers for academic and industrial research and development, mainly in advanced process control. The unconstrained MPC method presented here is based on [18]. Rewriting the motion equation of the 2-dof system in a state space form gives the state equation (9) and output equation (10):

$\left\{\dot{q}_{4 \times 1}\right\}=\left\{\begin{array}{l}\dot{x}_{2 \times 1} \\ \ddot{x}_{2 \times 1}\end{array}\right\}=$

$\left[\begin{array}{cc}O_{2 \times 2} & I_{2 \times 2} \\ -M_{2 \times 2}^{-1} \cdot K_{2 \times 2} & -M_{2 \times 2}^{-1} \cdot C_{2 \times 2}\end{array}\right] \cdot\left\{\begin{array}{l}x_{2 \times 1} \\ \dot{x}_{2 \times 1}\end{array}\right\}+$ the first equation is written as:

$\left\{\dot{q}_{4 x 1}\right\}=\left[A_{4 \times 4}\right] .\left\{q_{4 \times 1}\right\}+\left[B_{4 x 1}\right] .\left\{u_{1 \times 1}\right\}$.

The discrete time equation can then be expressed, sampled at equal intervals $\Delta t$, with $D_{s s}=[0]$, as:

$\{q[k+1 \mid k]\}=[\Phi] \cdot\{q[k \mid k-1]\}+\left[\Gamma_{u}\right] \cdot\{u[k \mid k-$

$1]+$ Гe.e $[k \mid k]$,

$\{d[k \mid k-1]\}=\left[C_{s s}\right] .\{q[k \mid k-1]\}$.

And

$\left[\Phi_{4 \times 4}\right]=e^{\mathrm{A} . \Delta \mathrm{t}}=\sum_{\mathrm{n}=0}^{\infty} \frac{(\mathrm{A} . \Delta \mathrm{t})^{\mathrm{n}}}{\mathrm{n} !}$ is the matrix exponential. For small time steps, $\mathrm{e}^{\mathrm{A} . \Delta \mathrm{t}} \cong \mathrm{I}_{4 \times 4}+\mathrm{A}_{4 \times 4} \cdot \Delta \mathrm{t}$, where $\mathrm{I}_{4 \times 4}$ is the identity matrix;

$\left[\Gamma_{\mathrm{u}}\right]=\mathrm{A}^{-1} \cdot\left(\mathrm{e}^{\mathrm{A} . \Delta \mathrm{t}}-1\right) \cdot \mathrm{B}$ is a constant $(4 \mathrm{x} 1)$ vector;

$\left[\Gamma_{\mathrm{e}}\right]$ is a constant estimator gain vector $(4 \mathrm{x} 1)$; and

$\mathrm{e}[\mathrm{k} \mid \mathrm{k}]=\mathrm{d}^{*}[\mathrm{k}]-\mathrm{d}[\mathrm{k} \mid \mathrm{k}-1]$, which $\mathrm{d}^{*}[\mathrm{k}]$ is the desired output signal.

To define the force control for each time instant, a control objective function is written as

$J_{M P C}=\frac{1}{2}\left[\psi[k]-\psi^{*}[k]\right]^{T} \cdot Q \cdot\left[\psi[k]-\psi^{*}[k]\right]+$

$\frac{1}{2} u^{T}[k] \cdot R \cdot u[k]$,

where,

$\psi[k]=\left[\begin{array}{llll}d^{T}[k+1 \mid k] & d^{T}[k+2 \mid k] \quad \ldots & d^{T}[k+p \mid k\end{array}\right]^{T}$

and

$\psi^{*}[\mathrm{k}]=$

$\left[\mathrm{d}^{* \mathrm{~T}}[\mathrm{k}+1 \mid \mathrm{k}] \quad \mathrm{d}^{* \mathrm{~T}}[\mathrm{k}+2 \mid \mathrm{k}] \quad \ldots \quad \mathrm{d}^{* \mathrm{~T}}[\mathrm{k}+\mathrm{p} \mid \mathrm{k}]\right]^{\mathrm{T}} \quad$ are (px1) vectors. $p$ is the number of step-ahead predictions of the output signal, known as the prediction horizon. 
Based on minimizing equation (15), the optimal predictive control force is given by

$u[k]=$

$\left[H^{T} \cdot Q_{M P C} \cdot H+\right.$

RMPC-1.HT.QMPC.YZ.qkk-1+Ye.e[k|k],

The elements of matrix $\mathrm{H}$ (pxm) are given by $\mathrm{h}_{\mathrm{i}}=$ C. $\Phi^{\mathrm{i}-1} \cdot \Gamma_{\mathrm{u}}(1 \times 1)$ and written as equation (17), where $\mathrm{m}$ is the control horizon, step-ahead prediction of the force.

$H=\left[\begin{array}{cccc}h_{1} & 0 & \cdots & 0 \\ h_{2} & h_{1} & \cdots & 0 \\ \vdots & & & \vdots \\ h_{p} & h_{p-1} & \cdots & h_{p-m+1}\end{array}\right]$

And

$$
\begin{aligned}
& Y_{z}=\left[[C . \Phi]^{T} \quad\left[C . \Phi^{2}\right]^{T} \quad \cdots \quad\left[C . \Phi^{p}\right]^{T}\right]^{T} \text { a matrix } \\
& \text { (px4), } \\
& Y_{e}= \\
& {\left[C . \Gamma_{e}\right]^{T} \quad[C .(I+} \\
& \text { Ф.ГеT ‥ C.k=1pФk-1.ГeT Ta vector (px1), } \\
& Q_{M P C}=\left[\begin{array}{ccc}
\bar{q} & \cdots & 0 \\
\vdots & & \vdots \\
0 & \cdots & \bar{q}
\end{array}\right] \text { a matrix }(p x p) \text {, for 2-dof } \\
& \text { problem, } \bar{q}=\left[\begin{array}{ll}
1 & 0 \\
0 & 0
\end{array}\right] \text {, } \\
& R_{M P C}=\lambda \cdot\left[\begin{array}{ccc}
1 & \cdots & 0 \\
\vdots & & \vdots \\
0 & \cdots & 1
\end{array}\right] \text { a matrix }((p-m+1) x(p- \\
& m+1) \text {. }
\end{aligned}
$$

$\lambda$ is a weighting on the rate of change of the inputs. For small penalties, the controller tends to give higher values and is less robust, while for large penalties it becomes a more robust controller but with a slow response [19]. The configuration values of the controller for the simulations consist of a state prediction horizon of $p=100$, control horizon of $\mathrm{m}=20$ and weighting of $\lambda=5 \times 10^{-4}$.

\subsection{Linear Quadratic Regulator Control}

The linear quadratic regulator (LQR) controller is one of the optimal control techniques used in engineering design and applications. The algorithm chooses weighting factors as a matrix of a linear state-feedback gain [20]. Mathematically, a LQR is defined as a cost function by

$J_{L Q R}=\int\left(\{q\}^{T} \cdot\left[Q_{L Q R}\right] \cdot\{q\}+\{u\}^{T} \cdot\left[R_{L Q R}\right] \cdot\{u\}\right) d t$

where, $\mathrm{Q}_{\mathrm{LQR}}(\mathrm{n} \times \mathrm{n})$ and $\mathrm{R}_{\mathrm{LQR}}(\mathrm{r} \times \mathrm{r})$ are a positive-definite Hermitian matrix, and a performance index is described by

$J_{L Q R}=\int\left[K_{L Q R}(q, u)\right] \cdot d t$, where,

choose $K_{L Q R}$ to minimize $J_{L Q R}=$

$\int\left(\{q\}^{T} \cdot\left[Q_{L Q R}\right] \cdot\{q\}+\{u\}^{T} \cdot\left[R_{L Q R}\right] \cdot\{u\}\right) d t$.

The optimal controller force, for any initial state, is given as

$\{u(t)\}=-\left[K_{L Q R}\right] \cdot\{q\}$.

For the optimization problem the following expression is chosen, where $\mathrm{P}$ is a symmetric and positive-definite matrix.

$q^{T} \cdot\left([Q]+\left[K_{L Q R}\right]^{T} \cdot[R] \cdot\left[K_{L Q R}\right]\right) \cdot\{q\}=$

$=-2 \cdot\{q\}^{T} \cdot[P] \cdot\{\dot{q}\}$.

For the negative real parts of the eigenvalues of $[\mathrm{A}]-$ $[B] .\left[K_{\mathrm{LQR}}\right]$, the system is asymptotically stable and thus the first term is zero, $\mathrm{q}(\infty) \rightarrow 0$. Therefore,

$J_{L Q R}=\{q(0)\}^{T} \cdot[P] \cdot\{q(0)\}$.

In order to minimize $\mathrm{J}_{\mathrm{LQR}}$, where $\mathrm{q}(0)$ is a constant vector, the matrix $[\mathrm{P}]$ should be minimized with respect to $\mathrm{K}_{\mathrm{LQR}}$ : $\frac{\partial \mathrm{P}}{\partial \mathrm{K}_{\mathrm{LQR}}}=0$. Hence,

$\left[K_{L Q R}\right]=[R]^{-1} \cdot[B]^{T} \cdot[P]$.

The expression in equation (24) gives the static LQR gain matrix and the matrix $[\mathrm{P}]$ is obtained by a backward numerical solution of the algebraic Riccati equation, using standard numerical tools in linear algebra:

$A^{T} \cdot P+P \cdot A-P \cdot B \cdot R^{-1} \cdot B^{T} \cdot P+Q=0$.

The input matrix is assumed as $Q=1 \times 10^{5} \cdot\left[\begin{array}{cccc}1 & 0 & 0 & 0 \\ 0 & 1 & 0 & 0 \\ 0 & 0 & 1 & 0 \\ 0 & 0 & 0 & 1\end{array}\right]$ and $\mathrm{R}=2.5 \times 10^{-4} \cdot\left[\begin{array}{ll}1 & 0 \\ 0 & 1\end{array}\right]$

\section{ROAD EXCITATION FORCES}

The roughness of a road is considered a source of external excitation of the vehicle with, for instance, forces acting on the tire. In this simulation, an asymmetrical excitation is used for the passage of the right wheels of a vehicle over a speed bump (case 1) and a vehicle passing over an uneven road profile (case 2), as seen in Fig. 3. The longitudinal speed of the vehicle is constant at $20 \mathrm{~km} / \mathrm{h}$. The bump model, case 1 , is a sinusoidal profile with a wavelength of $2.1=$ $3.0 \mathrm{~m}$ and height of $\mathrm{h}=0.080 \mathrm{~m}$. The (right) frontal wheel travels a distance of $0.5 \mathrm{~m}$ before the excitation starts. To represent the general road excitation in case 2, a white noise signal is filtered through a low-pass first-order filter. The cutoff frequency is $f_{c}=f_{o}^{\prime} . v$, where $f_{o}^{\prime}[c y c l e / m]$ is a cutoff spatial frequency and $\mathrm{v}[\mathrm{m} / \mathrm{s}]$ is the constant velocity of the 
vehicle. The power spectral density (PSD) of the road displacement $\left(\mathrm{S}_{\mathrm{r}}\right)$ is given by equation (26), [21]:

$S_{r}\left(f^{\prime}\right)=S_{o} \cdot\left[\frac{1 / f^{\prime} 2}{1+\left(f_{0}^{\prime} / f^{\prime}\right)^{2}}\right]$.

The parameter $S_{0}$ is a roughness magnitude and it is calculated using the signal standard deviation $\sigma$ as $\mathrm{S}_{0}=$ $\left(\sigma . \mathrm{f}_{\mathrm{o}}^{\prime}\right)^{2}$. The $\mathrm{f}^{\prime}[$ cycles $/ \mathrm{m}]$ is the spatial frequency, a division between frequency and velocity, $\mathrm{f}^{\prime}=\mathrm{f} / \mathrm{v}$.

The road excitation frequency in the range of $0.11 \mathrm{~Hz}$ is given by $\mathrm{S}_{\mathrm{o}}=1.25 \times 10^{-2}$ and $\mathrm{f}_{\mathrm{o}}{ }^{\prime}=0.02 \mathrm{cycle} / \mathrm{m}$ at a speed of $20 \mathrm{~km} / \mathrm{h}$.
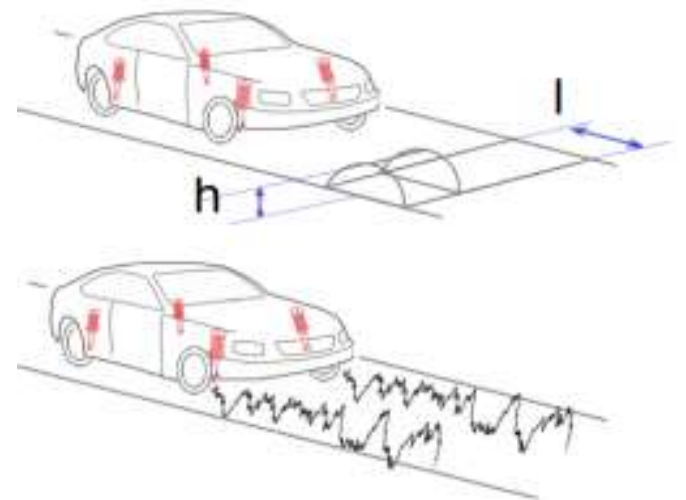

Fig 3: Profile of the speed bump (case 1) and uneven road excitation (case 2)

\section{RESULTS AND DISCUSSIONS}

This section reports the vehicle response in cases 1 and 2 in the dynamic simulation of 7 dof and using three different control methods. A delay time of $10 \mathrm{~ms}$ in the control force was employed in the numerical integration using the Newmark integrator with a sample rate of $1000 \mathrm{~Hz}$. The data collected were analyzed using the vibration displacement of the vehicle center of gravity (CG) and the integral squared error (ISE) of the controllers. Additionally, a sensitivity analysis was carried out to observe the interdependence and correlation between the controller parameters. For these evaluations, a design of experiments was employed with the Monte Carlo simulation.

\subsection{Vehicle Response from 7-dof Model}

The focus of the active suspension, in this case, is to provide vibration control and improve the internal comfort by reducing the oscillatory movements of the sprung mass. Fig. 4 shows the displacement of the vehicle center of gravity (CG) - bounce (heave) movement - on passing over the right side bump (case 1) and compares how the different controllers act. This illustrates the variation that can be generated in the controlled system, where the vehicle response with passive suspension has a higher vibration peak, while the controllers reduce this amplitude. The PID and MPC controls have similar behaviors, decreasing the overshoot to almost a third and shortening the settling time by half. In general, the response with the LQR control was of lower amplitude, but it had a low decay ratio.

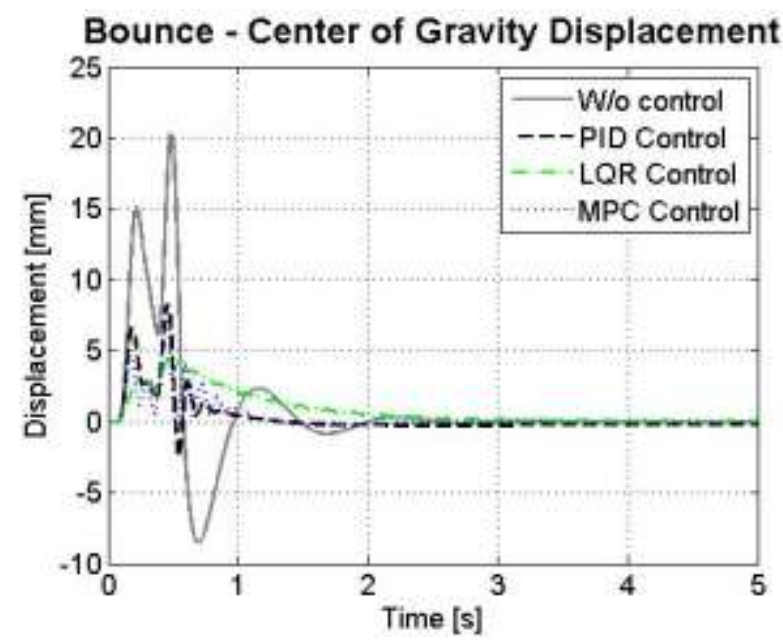

Fig 4: Displacement of vehicle center of gravity or bounce during passage over bump for different control methods

In order to analyze a random excitation response for each controller, an uneven road profile was applied to the 7-dof model. The road profile spectrum (power spectrum density) is provided in Fig. 5 and the road classification provided by ISO 8608 lies between letters " $\mathrm{A}$ " and " $\mathrm{H}$ ". For this simulation, the PSD profile operates at levels "C" and " $D$ ", between an average and poorly paved road profile [22].

At the end of this simulation of the random profile excitation, the vehicle CG displacements in Fig. 6, controlled by these methods, are noticeably smoother and have lower amplitude compared with the passive suspension. Once again, the vibration attenuations of the PID and MPC controllers were found to be similar.

Interestingly, the performance of the controllers is analyzed with the integral squared error (ISE) as an index given by

$I S E=\int_{0}^{T} e^{2}(t) \cdot d t$,

in which $\mathrm{e}(\mathrm{t})$ is the error between the desired and actual output values.

The ISE observed as a result of cases 1 and 2 in Table 4 shows attenuations of over $70 \%$, when compared with the passive suspension. Based on these results, the three control techniques investigated in this study achieved valuable dynamic control, attenuating the sprung mass vibration.

It is important to note that these results are specific to the quarter car model used in these simulations. Thus, application to cases other than the values of the 2-dof model parameters employed here may lead to different responses, resulting from variations in the more sensitive parameters, limiting the effectiveness of the controllers.

Table 4: Comparisons between different control methods considering the integral squared error (ISE) 


\begin{tabular}{|l|c|c|c|c|}
\hline \multicolumn{1}{|c|}{ ISE } & $\begin{array}{c}\text { Speed } \\
\text { bump } \\
\left(\boldsymbol{x} \mathbf{1 0}^{-\mathbf{6}}\right)\end{array}$ & $\begin{array}{c}\text { Attenuati } \\
\text { on }\end{array}$ & $\begin{array}{c}\text { Uneven } \\
\text { road } \\
\left(\boldsymbol{x} \mathbf{1 0}^{-\mathbf{3}}\right)\end{array}$ & $\begin{array}{c}\text { Attenuati } \\
\text { on }\end{array}$ \\
\hline $\begin{array}{l}\text { W/o } \\
\text { control }\end{array}$ & 79.16 & - & 21.97 & - \\
\hline $\begin{array}{l}\text { PID } \\
\text { control }\end{array}$ & 9.35 & $88.2 \%$ & 3.71 & $83.1 \%$ \\
\hline $\begin{array}{l}\text { LQR } \\
\text { control }\end{array}$ & 9.81 & $87.6 \%$ & 5.57 & $74.6 \%$ \\
\hline $\begin{array}{l}\text { MPC } \\
\text { control }\end{array}$ & 6.51 & $91.8 \%$ & 2.88 & $86.9 \%$ \\
\hline
\end{tabular}

\subsection{Sensitivity of the Model Parameters}

Since the uncertainties associated with the vehicle are real, a non-adaptive controller method may be sensitive to variations in the system characteristics. For instance, the

sprung mass and the position of the CG are far from being constant values. Under such conditions, the controller performance can be inconsistent, as observed in simulation tests. Thus, the aim of this study was to apply a generic methodology to evaluate the controller, in an environment with a high level of uncertainty, via a numerical simulation using the Monte Carlo method and design of experiment (DoE) tools, sometimes called the numerical design of experiments (NDoE), instead of a combination of costly numerical modelling and numerous experiments [23]. In recent years, DoE has been recognized as an important tool for validation and system characterization, applying statistical approaches to experimental design and analysis. The behavior of an input parameter and its effect on a response can be investigated separately, and interactions between different factors that affect the system output can be highlighted.

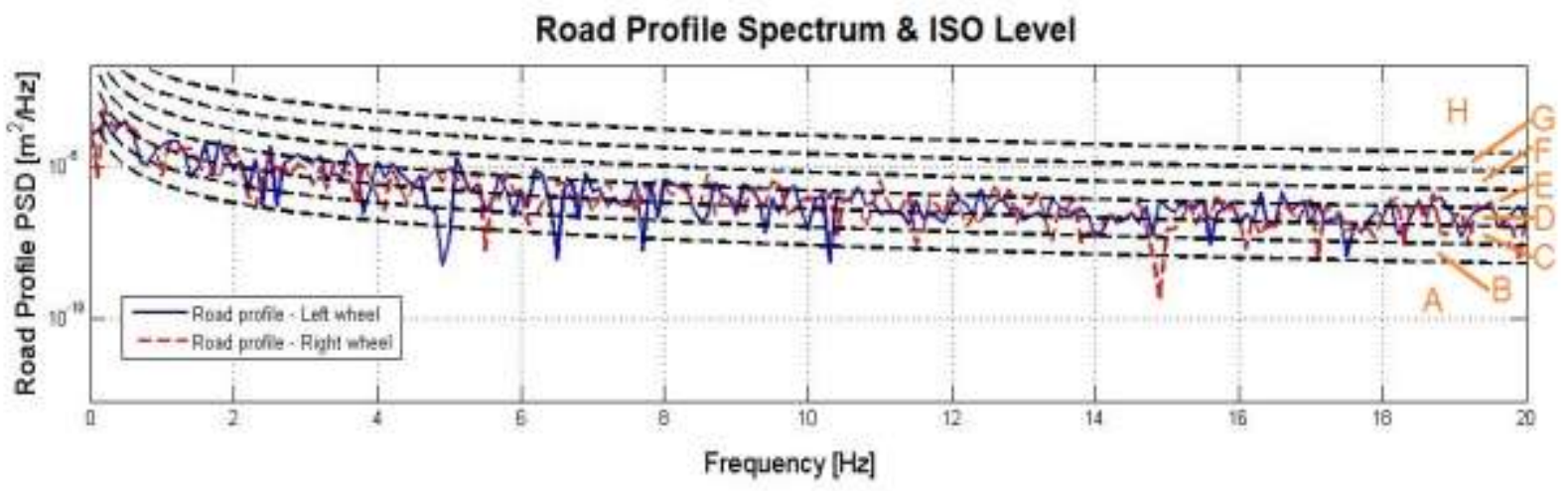

Fig 5: Power spectrum density for the uneven road profile

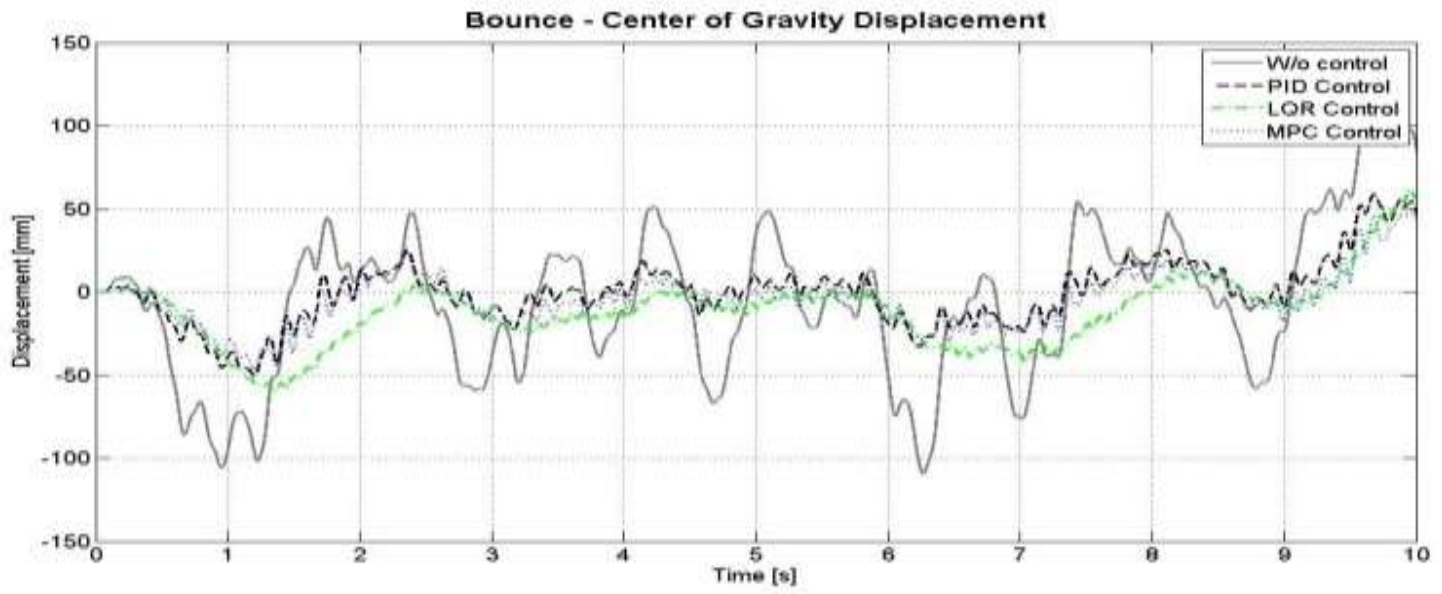

Fig 6: Displacement of the vehicle center of gravity or heave for the random road profile with different control methods

The Monte Carlo method is applied to compute a stochastic simulation with seven dof of vehicle vibration with PID, LQR and MPC controllers. The simulation employs the application of random numbers, which are normally distributed values for the front and rear stiffness, front and rear damping coefficients and sprung mass (Table 5). In this way, sampling experiments, associated with the uncertain behavior of the system, can be generated. In order to gain a better understanding of the effect of variations in the system characteristics on the performance of an active suspension controller, the design of experiments provides an important method to identify the critical input parameters. In this case, a $2^{5}$ full-factorial design was applied with 10 replications for the parameters described in Table 5 .

Table 5: Mean and standard deviation of two levels of Monte Carlo inputs 


\begin{tabular}{|c|l|c|c|c|}
\hline Factor & Variable & $\begin{array}{c}\text { Mean } \\
\text { Level 1 }\end{array}$ & $\begin{array}{c}\text { Mean } \\
\text { Level 2 }\end{array}$ & $\begin{array}{c}\text { Standard } \\
\text { Deviation }\end{array}$ \\
\hline (a) & $\begin{array}{l}\text { Sprung } \\
\text { mass } \\
\text { (kg) }\end{array}$ & 678.0 & 1078.0 & 100.0 \\
\hline (b) & $\begin{array}{l}\text { Front } \\
\text { stiffness } \\
\text { (N/m) }\end{array}$ & $13,700.0$ & $16,878.0$ & $1,500.0$ \\
\hline (c) & $\begin{array}{l}\text { Rear } \\
\text { stiffness } \\
(\mathrm{N} / \mathrm{m})\end{array}$ & $15,810.0$ & $19,000.0$ & $1,500.0$ \\
\hline (d) & $\begin{array}{l}\text { Front } \\
\text { damping } \\
\text { (Ns/m) }\end{array}$ & $1,300.0$ & $1,554.0$ & 150.0 \\
\hline (e) & $\begin{array}{l}\text { Rear } \\
\text { damping } \\
\text { (Ns/m) }\end{array}$ & $2,700.0$ & $3,144.0$ & 150.0 \\
\hline
\end{tabular}

The DoE evaluated with two levels receives lower (-1) and higher (+1) values for each parameter and the statistical correlation is calculated. The parameter sensitivity can be obtained by linear regression in the form of:

$Y=X \cdot \beta+\epsilon$,

where, $\mathrm{X}$ is the DoE matrix from Table 6 (see Appendix for table of results), $\beta$ are the coefficients of the surface lines, $\epsilon$ is the regression error and $\mathrm{Y}$ is the ISE value from the controlled suspension output signals.

Table 6: DoE matrix (-1) represents the lower level and $(+1)$ the higher level of the parameters

\begin{tabular}{|c|c|c|c|c|c|}
\hline & $\begin{array}{c}\text { Sprun } \\
\text { g } \\
\text { mass } \\
\left(m_{s}\right)\end{array}$ & $\begin{array}{c}\text { Front } \\
\text { stiffnes } \\
\text { s } \\
\left(k_{1}=\right. \\
\left.k_{2}\right)\end{array}$ & $\begin{array}{c}\text { Rear } \\
\text { stiffnes } \\
\text { s } \\
\left(\boldsymbol{k}_{3}=\right. \\
\left.\boldsymbol{k}_{4}\right)\end{array}$ & $\begin{array}{c}\text { Front } \\
\text { dampin } \\
\mathbf{g} \\
\left(c_{1}=\right. \\
\left.c_{2}\right)\end{array}$ & $\begin{array}{c}\text { Rear } \\
\text { dampin } \\
\mathbf{g} \\
\left(c_{3}=\right. \\
\left.c_{4}\right)\end{array}$ \\
\hline $\begin{array}{c}\text { Test } \\
\text { s }\end{array}$ & $a$ & $\boldsymbol{b}$ & $\boldsymbol{c}$ & $d$ & $e$ \\
\hline 1 & -1 & -1 & -1 & -1 & -1 \\
\hline 2 & -1 & -1 & -1 & -1 & +1 \\
\hline 3 & -1 & -1 & -1 & +1 & -1 \\
\hline 4 & -1 & -1 & -1 & +1 & +1 \\
\hline 5 & -1 & -1 & +1 & -1 & -1 \\
\hline 6 & -1 & -1 & +1 & -1 & +1 \\
\hline 7 & -1 & -1 & +1 & +1 & -1 \\
\hline 8 & -1 & -1 & +1 & +1 & +1 \\
\hline 9 & -1 & +1 & -1 & -1 & -1 \\
\hline 10 & -1 & $\begin{array}{r}+1 \\
\end{array}$ & -1 & -1 & +1 \\
\hline 11 & -1 & +1 & -1 & +1 & -1 \\
\hline 12 & -1 & +1 & -1 & +1 & +1 \\
\hline 13 & -1 & +1 & +1 & -1 & -1 \\
\hline 14 & -1 & +1 & +1 & -1 & +1 \\
\hline 15 & -1 & +1 & +1 & +1 & -1 \\
\hline 16 & -1 & +1 & +1 & +1 & +1 \\
\hline 17 & +1 & -1 & -1 & -1 & -1 \\
\hline
\end{tabular}

Table 7: Linear regression t-tests for PID, MPC and LQR controllers in case 2. Significance for $\mathrm{p}$-value $<0.05$

\begin{tabular}{|c|c|c|c|c|c|}
\hline 18 & +1 & -1 & -1 & -1 & +1 \\
\hline 19 & +1 & -1 & -1 & +1 & -1 \\
\hline 20 & +1 & -1 & -1 & +1 & +1 \\
\hline 21 & +1 & -1 & +1 & -1 & -1 \\
\hline 22 & +1 & -1 & +1 & -1 & +1 \\
\hline 23 & +1 & -1 & +1 & +1 & -1 \\
\hline 24 & +1 & -1 & +1 & +1 & +1 \\
\hline 25 & +1 & +1 & -1 & -1 & -1 \\
\hline 26 & +1 & +1 & -1 & -1 & +1 \\
\hline 27 & +1 & +1 & -1 & +1 & -1 \\
\hline 28 & +1 & +1 & -1 & +1 & +1 \\
\hline 29 & +1 & +1 & +1 & -1 & -1 \\
\hline 30 & +1 & +1 & +1 & -1 & +1 \\
\hline 31 & +1 & +1 & +1 & +1 & -1 \\
\hline 32 & +1 & +1 & +1 & +1 & +1 \\
\hline
\end{tabular}

Testing with every combination of the five factors shown in Table 6 required simulation with 32 conditions. The total number of simulations for 10 replications is 320 runs. The results of the t-statistical analysis for a two-tail distribution, the beta values determined (linear regression coefficients) and the p-values for each parameter and its crosscorrelation, are given in Table 7 (see Appendix for table of results). The controller parameters were found to have a very significant impact on the performance, with a p-value of less than $\alpha=5 \%$ (95\% of the confidence interval for $\widehat{\beta}_{\mathrm{j}}$ ). This sensitivity parameter can be defined as the average response to the factor, changing between low and high levels. This is summarized by the statement:

null hypothesis $H_{o}: \hat{\beta}_{j}=0$

and alternative hypothesis, $H_{a}: \hat{\beta}_{j} \neq 0$

where, $H_{o}$ is rejected if $\left|t_{o}\right|>t_{\left(\frac{\alpha}{2}, n-k-1\right)}$, otherwise the null hypothesis is accepted. $\mathrm{n}$ is the number of observations and $\mathrm{k}$ the number of variables.

It is clear from Table 7 that for each controller the most sensitive parameters differ. Front stiffness (b) and rear damping (e) had significant effects in terms of the ISE value for the PID control, while sprung mass (a), front stiffness (b) and rear damping (e) were important for the MPC control, and sprung mass (a) for the LQR control. In addition, this study permits the quantification of parameter interactions in cross product terms, as found for the sprung mass and front stiffness of the PID and LQR controls. Other parameters show no or little interaction. 


\begin{tabular}{|c|c|c|c|c|c|c|}
\hline \multirow[b]{2}{*}{ Variable } & \multicolumn{2}{|c|}{ PID } & \multicolumn{2}{|c|}{ MPC } & \multicolumn{2}{|c|}{ LQR } \\
\hline & $\widehat{\beta}_{j} \times 10^{3}$ & p-value & $\widehat{\beta}_{j} \times 10^{3}$ & p-value & $\widehat{\beta}_{j} \times 10^{3}$ & p-value \\
\hline Mean & 2.5486 & $\mathbf{0}$ & 2.1904 & $\mathbf{0}$ & 7.1459 & $\mathbf{0}$ \\
\hline$a$ & -0.1073 & 0.1021 & -0.1804 & 0.0006 & -0.4952 & 0.0116 \\
\hline$b$ & 0.2036 & 0.0020 & 0.1512 & 0.0040 & 0.3001 & 0.1248 \\
\hline c & 0.0803 & 0.2207 & 0.0777 & 0.1367 & 0.1157 & 0.5532 \\
\hline$d$ & -0.0134 & 0.8379 & -0.0233 & 0.6544 & -0.1620 & 0.4067 \\
\hline$e$ & 0.1550 & 0.0184 & 0.1143 & 0.0290 & 0.3258 & 0.0957 \\
\hline$a . b$ & -0.1550 & 0.0184 & -0.0975 & 0.0621 & -0.3927 & 0.0449 \\
\hline a.c & -0.0092 & 0.8877 & 0.0264 & 0.6123 & 0.0196 & 0.9200 \\
\hline a.d & 0.0134 & 0.8376 & 0.0238 & 0.6483 & 0.1426 & 0.4652 \\
\hline a.e & 0.0290 & 0.6579 & 0.0380 & 0.4663 & 0.1948 & 0.3186 \\
\hline$b . c$ & 0.0140 & 0.8302 & 0.0061 & 0.9063 & 0.0673 & 0.7302 \\
\hline b.d & -0.0976 & 0.1366 & -0.0690 & 0.1861 & -0.2554 & 0.1911 \\
\hline$b . e$ & 0.1070 & 0.1028 & 0.0799 & 0.1263 & 0.3765 & 0.0544 \\
\hline c.d & 0.0450 & 0.4921 & 0.0216 & 0.6789 & -0.0053 & 0.9784 \\
\hline c.e & 0.0793 & 0.2261 & 0.0473 & 0.3645 & 0.1439 & 0.4611 \\
\hline d.e & -0.0366 & 0.5758 & -0.0347 & 0.5057 & -0.0782 & 0.6888 \\
\hline a.b.c & -0.0957 & 0.1446 & -0.0513 & 0.3255 & -0.2062 & 0.2910 \\
\hline$a . b . d$ & 0.0400 & 0.5414 & 0.0380 & 0.4663 & 0.1986 & 0.3093 \\
\hline a.b.e & -0.0063 & 0.9232 & -0.0014 & 0.9791 & -0.1858 & 0.3413 \\
\hline b.c.d & 0.0293 & 0.6549 & 0.0487 & 0.3503 & 0.2127 & 0.2762 \\
\hline b.c.e & 0.0986 & 0.1329 & 0.0619 & 0.2356 & 0.3058 & 0.1178 \\
\hline c.d.e & 0.0357 & 0.5854 & 0.0385 & 0.4602 & 0.1222 & 0.5314 \\
\hline d.e. $a$ & 0.0455 & 0.4877 & 0.0019 & 0.9709 & -0.0255 & 0.8961 \\
\hline d.e.b & -0.0067 & 0.9186 & 0.0028 & 0.9570 & 0.0204 & 0.9168 \\
\hline c.d.a & 0.0599 & 0.3608 & 0.0510 & 0.3283 & 0.2071 & 0.2890 \\
\hline e.a.c & -0.0302 & 0.6451 & -0.0251 & 0.6297 & -0.1153 & 0.5545 \\
\hline a.b.c.d & -0.0268 & 0.6819 & -0.0244 & 0.6396 & -0.0775 & 0.6911 \\
\hline a.b.c.e & -0.0700 & 0.2856 & -0.0343 & 0.5103 & -0.1196 & 0.5399 \\
\hline b.c.d.e & -0.0610 & 0.3517 & -0.0255 & 0.6247 & -0.0644 & 0.7413 \\
\hline c.d.e.a & -0.0297 & 0.6503 & -0.0409 & 0.4332 & -0.2541 & 0.1935 \\
\hline d.e.a.b & 0.0208 & 0.7508 & 0.0451 & 0.3870 & 0.0365 & 0.8515 \\
\hline a.b.c.d.e & 0.0221 & 0.7352 & 0.0176 & 0.7363 & 0.0871 & 0.6554 \\
\hline
\end{tabular}

In the interaction plots in Fig. 7 to 9, the factor interdependence can be observed. The main diagonal represents the factor influence on the ISE values with a $\pm \sigma$ curve (one standard deviation). For the PID controller (Fig. 7), the main factor effects can be observed for (b) and (e), both showing an increase in ISE for higher values of the parameter. Similarly, the highest gradients found for MPC (Fig. 8) are for the factors (a) with a negative slope and (b) and (e) with positive slopes, and for LQR (Fig. 9) for factor (a) with a negative slope. The main interaction between factors occurs for variables (a) and (b), in the case of the PID and LQR controllers, and no apparent interactions are observed for the MPC controller.

Fig. 10 shows the factor level plots comparing the distributions of the ISE between two controller parameters. The column distribution (cyan square) illustrates the ISE variation from minimum and maximum values for each combination of factors. In all cases, there is a large variation in the values, indicating that the parameters with high uncertainty provoke changes in the controller performance.
Conversely, for the PID and MPC controllers the distribution generally lies below that of the control without the random parameters, so that the vibration attenuation was significantly higher than the original controller design. In contrast to the LQR controller, the ISE distribution changes scale significantly between the minimum value and the uncontrolled condition. Therefore, the higher vibration amplitude from some samples controlled by the LQR method indicates that it did not improve the suspension performance. 

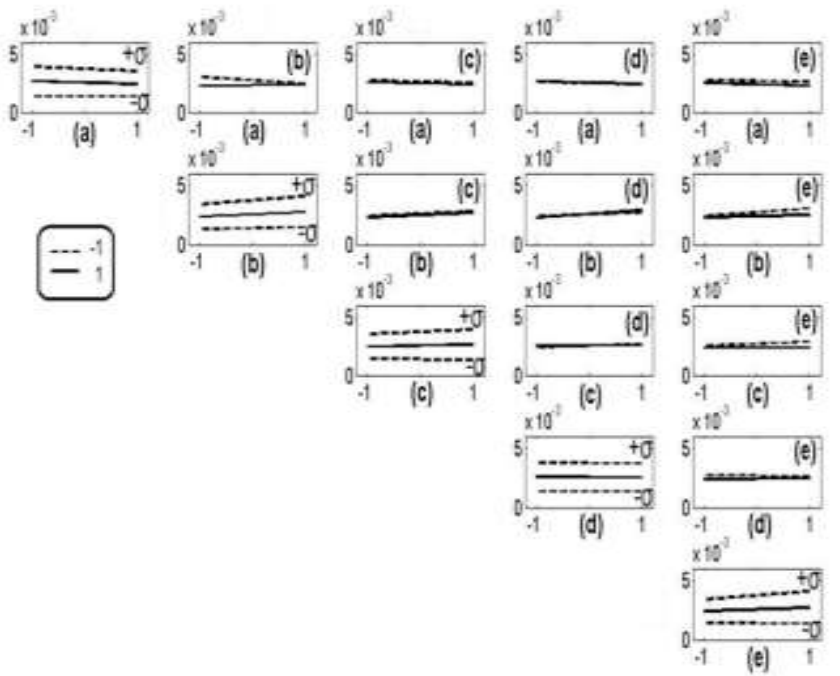

Fig 7: Interaction plot for ISE for the PID controller
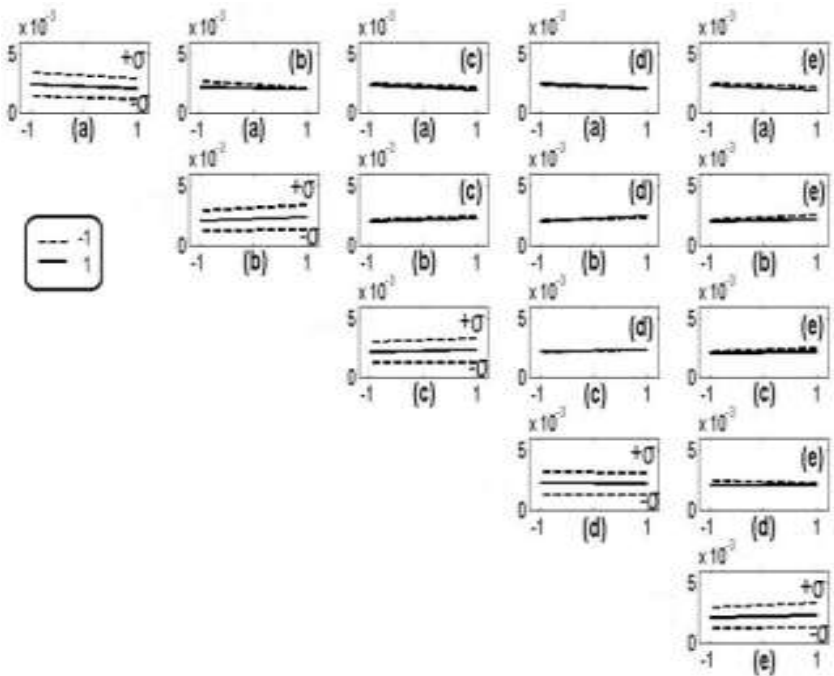

Fig 8: Interaction plot for ISE for the MPC controller

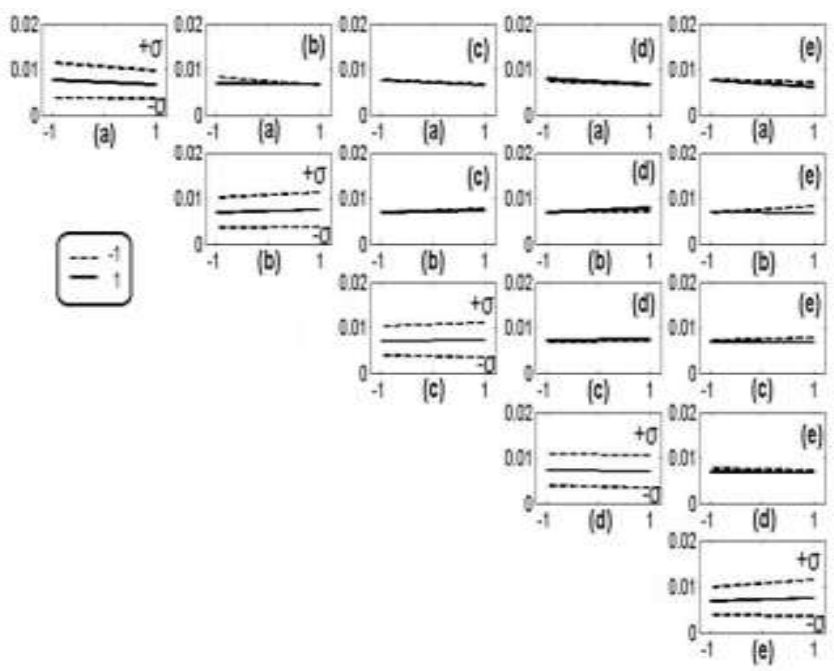

Fig 9: Interaction plot for ISE for the LQR controller
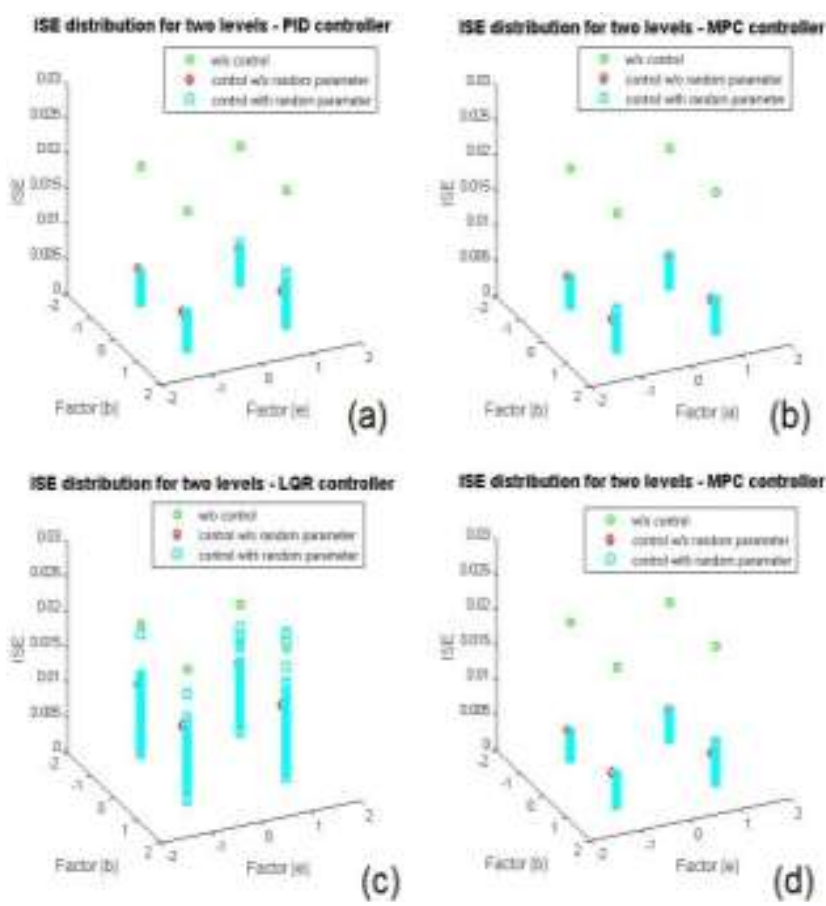

Fig 10: ISE distribution for interaction between parameters

Based on these results, the maximum attenuation of the sprung mass vibration using different controllers can be reduced or increased because of the uncertain and variable values attributed to the controller model parameters. However, the changes in the performance of the suspension controller are more pronounced only for specific parameters, indicating the need for further engineering research to investigate them.

\section{CONCLUSION}

When using a conventional control method to control the active suspension of a vehicle, considerable caution needs to be taken due to the effects associated with the model parameters. This paper presented a methodology and analyzes the relation between active suspension control and DoE, in order to provide a better understanding of the impact and interactions of the controller parameters with regard to the performance dynamics of the vehicle. The methodology is applied in a Monte Carlo simulation, which allows random factors to be established for statistical analysis. The method was applied on the uneven road profile (case 2), and the numerical simulations regarding the ISE values of the CG displacement were carried out to evaluate and compare three types of controllers: PID, MPC and LQR. As a result, the main effects and their interactions were identified. The sensitivity study using linear regression identified groups of factors for each controller, highlighting parameters with the strongest influence on the performance variation. These variations were found to have a random distribution, increasing or reducing the ISE value of the designed condition. In the extreme cases, the associated vibration attenuation in the sprung mass is greater than that of a passive suspension. This quantitative procedure for evaluating the controller provides a way for model analysis 
to be carried out and supports predictions regarding the behavior of the system dynamics. However, as reported herein, this is dependent on the control method chosen, as the variables of a 2-dof model are more sensitive to changes. It emerged, in general, that the sprung mass, front stiffness and rear damping have the greatest influence on the controllers investigated. However, it is significant that for the LQR method the attenuation observed is sometimes poor due to the model parameter uncertainty.

\section{REFERENCES}

[1] Poussot-Vassal, C., Spelta, C., Sename, O., Savaresi, S.M., Dugard, L.: 'Survey and performance evaluation on some automotive semi-active suspension control methods: A comparative study on a single-corner model', Annu. Rev. in Control, 2012, 36, pp. 148-160

[2] Suzuki, T., Takahashi, M.: 'Semi-Active Suspension Control System Design for Vibration Reduction of Passenger's Body Based on Lissajous Figure of Damping Force', Journal of System Design and Dynamics, 2011, 5, (2), pp. 279-295

[3] Du, H., Li, W., Zhang, N.: 'Integrated seat and suspension control for a quarter car with driver model', IEEE T. Veh. Technol., 2012, 61,(9), pp. 3893-3908

[4] Marofi, S.Ms., Seyedalian, S.J., Akram, L.: 'Improve active suspension system by FEL controller design', Mechanika, 2013, 19, (6), pp. 681-687

[5] Göhrle, C., Schindler, A., Wagner, A., et al.: 'Design and vehicle implementation of preview active suspension controllers', IEEE T Contr Syst T, 2014, 22, (3), pp. 1135-1142

[6] Li, P., Lam, J., Cheung, K.C.: 'Multi-objective control for active vehicle suspension with wheelbase preview', J. Sound Vib., 2014, 333, pp. 5269-5282

[7] ElMadany, M.M., Al Bassam, B.A., Fayed, A.A.: 'Preview control of slow-active suspension systems', J. Vib. Control, 2011, 17, (2), pp. 245-258

[8] Unger, A., Schimmack, F., Lohmann, B., et al.: 'Application of LQ-based semi-active suspension control in a vehicle', Control Eng. Pract., 2013,21, pp. 1841-1850

[9] Poussot-Vassal, C., Sename, C., Dugard, L., et al.: 'A new semi-active suspension control strategy through LPV technique', Control Eng. Pract., 2008, 16, pp. 1519-1534

[10] Canale, M., Milanese, M., Novara, C.: 'Semi-active suspension control using "fast" model-predictive techniques', IEEE T. Contr. Syst. T., 2006, 14, (6), pp. 1034-1046

[11] Zheng, L., Li, Y., Chen, B.: 'A new semi-active suspension control strategy through mixed $\mathrm{H} 2 / \mathrm{H} \infty$ robust technique', J. Cent. South Univ. T., 2010, 17, pp. 332-339

[12] Wang, R., Jing, H., Karimi, H.R., et al.: 'Robust fault-tolerant $\mathrm{H} \infty$ control of active suspension systems with finite-frequency constraint', Mech. Syst. Signal Process., 2015, 62, (63), pp. 341-355

[13] Choudhury, S.F., Sarkar, M.A.R.: 'An approach on performance comparison between automotive passive suspension and active suspension system (PID controller) using matlab/Simulink', Journal of Theoretical and Applied Information Technology, 2012, 43, (2), pp. 295-300

[14] Sweversa, J., Lauwerysa, C., Vandersmissenb, B., et al.: 'A model-free control structure for the on-line tuning of the semi-active suspension of a passenger car', Mech. Syst. Signal Process., 2007, 21, pp. 14221436

[15] Ieluzzi, M., Turco, P., Montiglio, M.: 'Development of a heavy truck semi-active suspension control', Control Eng. Pract., 2006, 14, pp. 305-312

[16] Huang, Y., Na, J., Wu, X., et al.: 'Adaptive control of nonlinear uncertain active suspension systems with prescribed performance', ISA T., 2015, 54, pp. 145155

[17] Jastrzebski, R.P., Hynynen, K.M., Smirnov, A.: 'Hळ control of active magnetic suspension', Mech. Syst. Signal Process., 2010, 24, pp. 995-1006

[18] Mei, G., Kareem, A., Kantor, J.C.: 'Real-time model predictive control', Earthq. Eng. Struct. D., 2001, 30, pp. 995-1019

[19] Garriga, J.L., Soroush, M.: 'Model Predictive Control Tuning Methods: A Review', Ind. Eng. Chem. Res., 2010, 49, pp. 3505-3515

[20] Nagarkar, M.P., Vikhe, G.J., Borole, K.R., et al.: 'Active control of quarter-car suspension system using linear quadratic regulator', International Journal of Automotive and Mechanical Engineering, 2011, 3, pp. 364-372

[21] Ulsoy, A.G., Peng, H., Çakmakci, M.: 'Automotive Control Systems' (University Press, Cambridge, UK, 2012)

[22] Loprencipe, G., Zoccali, P.: 'Use of generated artificial road profiles in road roughness evaluation', J. Mod. Transport., 2017, 25, (1), pp. 24-33

[23] Blondet, G. Duigou, J. L., Boudaoud, N., et al.: 'An ontology for numerical design of experiments processes', Comput. Ind., 2018, 94, pp. 26-40. 